\title{
Fluorescence probe properties of $N$-octadecamido compounds of tryptophan
}

\author{
Anil K. Singh*, Joydip Das \\ Department of Chemistry, Indian Institute of Technology, Powai, Mumbai 400 076, India
}

\begin{abstract}
Two new long chain tryptophan compounds viz [3-(indolyl-3')-2-( $N$-octadecamido)]-methylpropionate (4) and sodium-[3-(indolyl-3')-2( $N$-octadecamido)]-propionate (5) have been prepared and their fluorescence properties $\left(\lambda_{\max }, \phi_{\mathrm{f}}, \tau_{\mathrm{f}}, r_{\mathrm{ss}}\right.$, quenching) have been investigated in homogeneous media and in phosphatidyl choline vesicles. Both $\mathbf{4}$ and $\mathbf{5}$ in a membrane mimicking system of phosphatidylcholine vesicles show blue-shifted emission maxima but higher quantum yields of fluorescence as compared to tryptophan. The steady state anisotropy values show that the molecules are immobilised in the membrane. While both the fluorophores show single exponential fluorescence decay profile in homogeneous media, a triple exponential fluorescence decay is observed in vesicular medium. The fluorescence of both the compounds are quenched by retinyl polyenes viz. retinal and retinyl acetate. The extent of quenching is more in organised media of vesicles as compared to organic solvents. A comparison of the fluorescence data for $\mathbf{4}$ and $\mathbf{5}$ with those for retinalbinding protein bacteriorhodopsin and the apoprotein bacterioopsin reveals some similarities in the nature of interaction between retinylidene polyenes and $\mathbf{4}$ and $\mathbf{5}$, and between retinylidene Schiff base chromophore and tryptophan residues in the protein
\end{abstract}

Keywords: Fluorescence; Tryptophan; N-Octadecamidotryptophan

\section{Introduction}

The fluorescence properties of indolic compounds have been extensively studied because of the utility of the indole chromophore as an intrinsic probe for the microenvironment of proteins and enzymes [1,2]. Most of the studies have been directed to obtain information about location and excited state properties of these chromophores in biological systems. The indole containing tryptophan residues are believed to play an important role in anchoring of proteins in membrane. Studies using indole compounds have also been made to investigate the nature of water-tryptophan interactions in polypeptides and proteins spanning the membrane bilayer $[3,4]$. However, use of tryptophan as a probe is limited because of the fact that tryptophan has a nonexponential fluorescence decay, and more than one tryptophan residue is usually found in most proteins. Very recently some novel indole compounds such as $N$-alkylindoles capable of forming vesicles [5] and $N_{1}$-methyl-7-azatryptophan [6] showing single exponential long-lived fluorescence decay and high fluorescence quantum yield have been reported.

Herein we report synthesis and fluorescence studies of previously unreported tryptophan compounds viz, [3-(indolyl-3')-2-(N-octadecamido)]-methylpropionate (4) and sodium-[3-(indolyl-3')-2-( $N$-octadecamido)]-propionate (5), bearing long alkyl chains, which show fluorescence properties useful for their use as fluorescence probes. We have also studied the interaction of $\mathbf{4}$ and $\mathbf{5}$ with retinylidene polyenes which are known to undergo interaction with tryptophan and exhibit unique electrooptical features $[7,8]$.

\section{Experimental}

\subsection{General}

Tryptophan (1), stearic acid, sodium dodecyl sulphate (SDS) and cetyl trimethylammonium bromide (CTAB) were purchased from Sisco Research Laboratories, Mumbai, India. Retinal and retinol acetate were from Sigma (USA). L- $\alpha$-phosphatidylcholine was obtained from Centre for Biochemical Technology, New Delhi. UV-VIS measurements were made on a Shimadzu 160 spectrophotometer. IR 


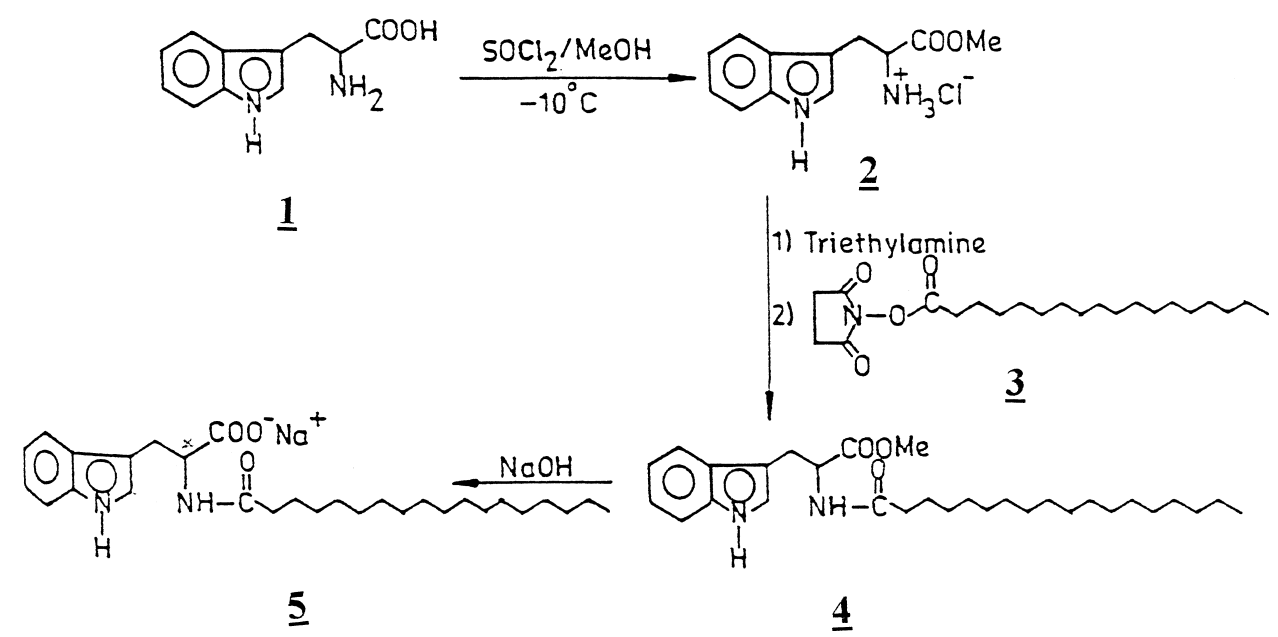

Scheme 1.

spectra were recorded on a Nicolet Impact 400 FTIR spectrophotometer. NMR spectra were recorded on a Varian VXR-500 MHz spectrometer. All solvents used were of analytical grade from Ms. Spectrochem, Mumbai. Micelles were prepared by dissolving the required amount of surfactants in deionized, double distilled water. Compounds $\mathbf{4}$ and 5 were incorporated in micelles by injecting tetrahydrofuran solutions $\left(3 \mu \mathrm{l}, 1 \times 10^{-2} \mathrm{M}\right)$ of $\mathbf{4}$ and $\mathbf{5}$ in micelles followed by brief sonication using Branson B-12 sonifier $(250 \mathrm{MHz}$, 5 min).

\subsection{Synthesis of compounds [3-(indolyl-3')-2-(N-} octadecamido)]-methylpropionate (4) and sodium-[3(indolyl-3')-2-(N-octadecamido)]-propionate (5)

Synthesis of $\mathbf{4}$ and $\mathbf{5}$ is outlined in Scheme 1. The hydrochloride salt (2) of the methyl ester of tryptophan was prepared as described elsewhere [9]. m.p.: $213-214^{\circ} \mathrm{C}$ (lit. [9] m.p.: 215-216 ${ }^{\circ}$ ).

\subsection{Preparation of the active ester (3) of stearic acid}

Stearic acid ( $2 \mathrm{~g}, 7.03 \mathrm{mmol})$ and $N$-hydroxysuccinimide $(0.8 \mathrm{~g}, 7.03 \mathrm{mmol})$ were taken in a round-bottomed flask and $35 \mathrm{ml}$ dry dimethylformamide (DMF) was added. The mixture was stirred and cooled to $0-5^{\circ} \mathrm{C}$ and dicyclohexylcarbodiimide (DCC, $1.45 \mathrm{~g}, 7.03 \mathrm{mmol}$ ) was added.The mixture was stirred for one and half hours at $0-5^{\circ} \mathrm{C}$. A small pinch of dimethylaminopyridine (DMAP) was also added to catalyse the reaction. Care was taken to avoid the contact of the reaction mixture with moisture. The mixture was kept overnight at $4^{\circ} \mathrm{C}$.

\subsection{Coupling of methylester (2) of tryptophan with the} active ester (3) of stearic acid

The hydrochloride of the methylester of tryptophan (2, $1.78 \mathrm{~g}, 7.03 \mathrm{mmol}$ ) was taken in DMF and was neutralised (to neutral $\mathrm{pH}, 7.0$ ) by triethylamine. Active ester 3, was then added and the mixture was kept overnight at $4{ }^{\circ} \mathrm{C}$. The reaction mixture was then brought back to room temperature and extracted thoroughly with diethylether. The diethylether layer was dried with anhydrous sodium sulphate and the diethylether was then evaporated. The solid organic material was subjected to column chromatography over $\mathrm{Al}_{2} \mathrm{O}_{3}$. Elution of the column with $30 \%$ ethyl acetate in petroleum ether $\left(60^{\circ}-80^{\circ} \mathrm{C}\right.$ fraction) gave [3-(indolyl- $\left.3^{\prime}\right)-2-(N$-octadecamido)]-methylpropionate (4) in $55 \%$ yield as white solid; m.p.: 87-88 ${ }^{\circ}$; UV-VIS, $\lambda_{\max }, \mathrm{nm}\left(\epsilon, 1 . \mathrm{mol}^{-1} \mathrm{~cm}^{-1}\right)$, $\mathrm{CHCl}_{3}$ : 274 (5231), 280 (5316), 290 (4279); IR (cm ${ }^{-1}$, nujol): 3368, 3335, 1736 (ester carbonyl), 1650 (amide band I), 1545 (amide band II); NMR (H[1], $500 \mathrm{MHz}, \mathrm{d}_{6}$-DMS): $8.20(1 \mathrm{H}, \mathrm{d}, 7.50 \mathrm{~Hz}$, amide-H), $7.48(1 \mathrm{H}, \mathrm{d}, 7.70 \mathrm{~Hz}$, aromatic), $7.33(1 \mathrm{H}, \mathrm{d}, 8.00 \mathrm{~Hz}$, aromatic $), 7.13(1 \mathrm{H}, \mathrm{s}$, aromatic), $7.05(1 \mathrm{H}, \mathrm{m}$, aromatic), $3.15(2 \mathrm{H}, \mathrm{m}, \beta-\mathrm{C}-\mathrm{H})$, $2.06(2 \mathrm{H}, \mathrm{m}$, aliphatic chain proton $), 1.41(2 \mathrm{H}, \mathrm{m}$, aliphatic chain proton), $1.24(30 \mathrm{H}, \mathrm{s}$, aliphatic chain protons), 0.85 ( $3 \mathrm{H}, \mathrm{m}$, aliphatic chain protons).

\subsection{Preparation of sodium-[3-indolyl-3 $\left.3^{\prime}\right)-2-(N-$ octadecamido)]-propionate (5)}

Compound $4(0.2 \mathrm{~g}, 0.04 \mathrm{mmol})$ was taken in a roundbottomed flask and dissolved in methanol-acetone $(10 \mathrm{ml}$, $60: 40)$ mixture. Sodium hydroxide solution (2 $\mathrm{M}$ in water) was added slowly with ice cooling and stirring (teflon). The disappearance of the original compound $\mathbf{4}$ was monitored by thin layer chromatography on silica gel with $30 \%$ ethyl acetate in petroleum ether $\left(60^{\circ}-80^{\circ} \mathrm{C}\right.$ fraction $)$ as solvent. The reaction was complete in about $2 \mathrm{~h}$. Methanol and acetone were evaporated and the remaining mixture was extracted with diethylether. After usual work-up, diethylether was evaporated and when the white, solid sodium-[3(indolyl-3')-2-( $N$-octadecamido)]-propionate (5) was obtained in $48 \%$ yield; m.p.:104-105 ${ }^{\circ}$; UV-VIS, $\lambda_{\max }$ in $\mathrm{nm}\left(\epsilon, 1 . \mathrm{mol}^{-1} \mathrm{~cm}^{-1}\right), \mathrm{MeOH}: 282$ (4523), 290 
(3854); IR ( $\mathrm{cm}^{-1}$, nujol): 3368, 1650 (amide band I), 1591 (acid carbonyl), 1545 (amide band II); NMR $\left(\mathrm{H}^{1}, 500 \mathrm{MHz}\right.$, d -DMSO : $7.45(1 \mathrm{H}, \mathrm{d}, 7.80 \mathrm{~Hz}$, amide-H), $7.25(1 \mathrm{H}, \mathrm{d}$, $8.00 \mathrm{~Hz}$, aromatic), $7.05(1 \mathrm{H}, \mathrm{d}, 7.00 \mathrm{~Hz}$, aromatic), 6.98 (2 $\mathrm{H}, \mathrm{m}$, aromatic), $6.87(1 \mathrm{H}, \mathrm{m}$, aromatic), $4.03(1 \mathrm{H}, \mathrm{m}$, $\alpha-\mathrm{C}-\mathrm{H}), 3.0(2 \mathrm{H}, \mathrm{m}, \beta-\mathrm{C}-\mathrm{H}), 1.96(2 \mathrm{H}, \mathrm{m}$, aliphatic chain proton), 1.38 ( $2 \mathrm{H}, \mathrm{m}$, aliphatic chain proton), $1.24(30 \mathrm{H}, \mathrm{s}$, aliphatic chain protons), $0.84(3 \mathrm{H}, \mathrm{m}$, aliphatic chain protons).

\subsection{Fluorescence studies}

The fluorescence spectra of compounds $\mathbf{4}$ and $\mathbf{5}$ were recorded in different organic solvents, in SDS and CTAB micelles, and in phosphatidylcholine vesicles. The incorporation of the compounds in vesicles were done by following the procedure as described elsewhere [10]. Concentrations of phosphatidylcholine and compounds 4 and 5 were kept at $1 \times 10^{-3}$ and $1 \times 10^{-5} \mathrm{M}$ respectively. Relative fluorescence quantum yields $\left(\phi_{\mathrm{f}}\right)$ were determined using L-tryptophan as standard $\left(\phi_{\mathrm{fs}}=0.135\right)[11,12]$. Fluorescence quenching studies were performed by addition of ethanolic solutions of retinal or retinol acetate $(3 \mu 1$, $4.37 \times 10^{-3} \mathrm{M}$ ) to the respective solutions of $\mathbf{4}$ and $\mathbf{5}$. The quenching constant values were determined taking the area of the emission spectra from $300 \mathrm{~nm}$ to $450 \mathrm{~nm}$. Steady state fluorescence measurements were carried out on a Spex Spectrofluorolog spectrofluorimeter with a $450 \mathrm{~W}$ xenon lamp as light source. Steady state anisotropies of compounds $\mathbf{4}$ and $\mathbf{5}$ in vesicles were measured by putting a WG305 filter at the emission monochromator to eliminate scattering due to vesicles. Lifetime measurements were done with a picosecond laser excited time-correlated single photon counting experimental set-up. The excitation light source was a tunable picosecond dye laser pumped synchronously by the frequency doubled output $(532 \mathrm{~nm})$ of the mode locked CW Nd-YAG laser from Spectraphysics, USA. The UV pulses were used to excite the sample held in a quartz cuvette of $1 \mathrm{~cm}$ [2] cross section. The emitted fluorescence was detected by MCP PMT 2809 U01 (Hamamatsu) and amplified by a preamplifier HP 8447F. The excitation wavelength used was $290 \mathrm{~nm}$. The instrument response had a full-width half maximum of $80 \mathrm{ps.} \mathrm{All} \mathrm{the}$ measurements were carried out at $25^{\circ} \mathrm{C}$. For the lifetime measurements the concentrations of compounds $\mathbf{4}$ and $\mathbf{5}$ were $3 \times 10^{-5} \mathrm{M}$.

\section{Results and discussion:}

\subsection{Fluorescence emission maxima and quantum yields of 4 and 5}

The fluorescence emission and excitation spectra of compound $\mathbf{4}$ are shown in Fig. 1. Fluorescence properties of compounds $\mathbf{4}$ and $\mathbf{5}$ are summarized in Table 1. Similar to indole fluorescence [13], the fluorescence maximum of $\mathbf{5}$ shifts towards the red when solvent polarity is increased (Fig. 2). In 50\% methanol-water, 5 shows an emission maximum at $366 \mathrm{~nm}$. However, in phosphatidylcholine vesicles the fluorescence maximum of 5 shifts to $348 \mathrm{~nm}$. In vesicular media, while tryptophan shows fluorescence band at $363 \mathrm{~nm}$, both compounds $\mathbf{4}$ and $\mathbf{5}$ show blue-shifted fluorescence maxima. Also, the relative quantum yield of fluorescence of $\mathbf{4}$ is higher in organised assemblies of micelles and vesicles. The Stokes shift value for $\mathbf{5}$ is found to be highest in $50 \%$ methanol-water mixture.

Table 1

Fluorescence data for [3-(indolyl-3')-2-(N-octadecamido)]-methylpropionate (4) and sodium-3[3-(indolyl-3')-2-( $N$-octadecamido)]propionate $(\mathbf{5})$ in different media at $25^{\circ} \mathrm{C}$

\begin{tabular}{|c|c|c|c|c|c|}
\hline Compound & Medium & $\lambda_{\mathrm{em}}(\mathrm{nm})$ & $\lambda_{\mathrm{ex}}(\mathrm{nm})$ & Stokes shift $\left(\mathrm{cm}^{-1}\right)$ & $\phi_{\mathrm{f}}$ \\
\hline \multirow[t]{5}{*}{4} & $\mathrm{CH}_{3} \mathrm{CN}$ & 345 & 281 & 6601 & 0.17 \\
\hline & EtOAc & 337 & 281 & 5913 & 0.11 \\
\hline & CTAB & 337 & 287 & 5169 & 0.29 \\
\hline & SDS & 334 & 289 & 4662 & 0.21 \\
\hline & Vesicle & 349 & 289 & 5949 & 0.18 \\
\hline \multirow[t]{6}{*}{5} & $\mathrm{MeOH}$ & 357 & 287 & 7450 & 0.20 \\
\hline & $50 \% \mathrm{MeOH}-\mathrm{H}_{2} \mathrm{O}$ & 366 & 282 & 8139 & 0.21 \\
\hline & THF & 339 & 283 & 5837 & 0.21 \\
\hline & CTAB & 355 & 284 & 7042 & 0.30 \\
\hline & SDS & 362 & 282 & 7837 & 0.24 \\
\hline & Vesicle & 348 & 284 & 6475 & 0.20 \\
\hline Tryptophan & $\mathrm{H}_{2} \mathrm{O}$ & 365 & 283 & 7938 & 0.14 \\
\hline
\end{tabular}

$\phi_{\mathrm{f}}= \pm 0.001 ; \lambda= \pm 2 \mathrm{~nm}$.

$[\mathrm{SDS}]=1 \times 10^{-2} \mathrm{M},[\mathrm{CTAB}]=1.0 \times 10^{-3} \mathrm{M}$, [phosphatidylcholine $]=1 \times 10^{-3} \mathrm{M}$. 

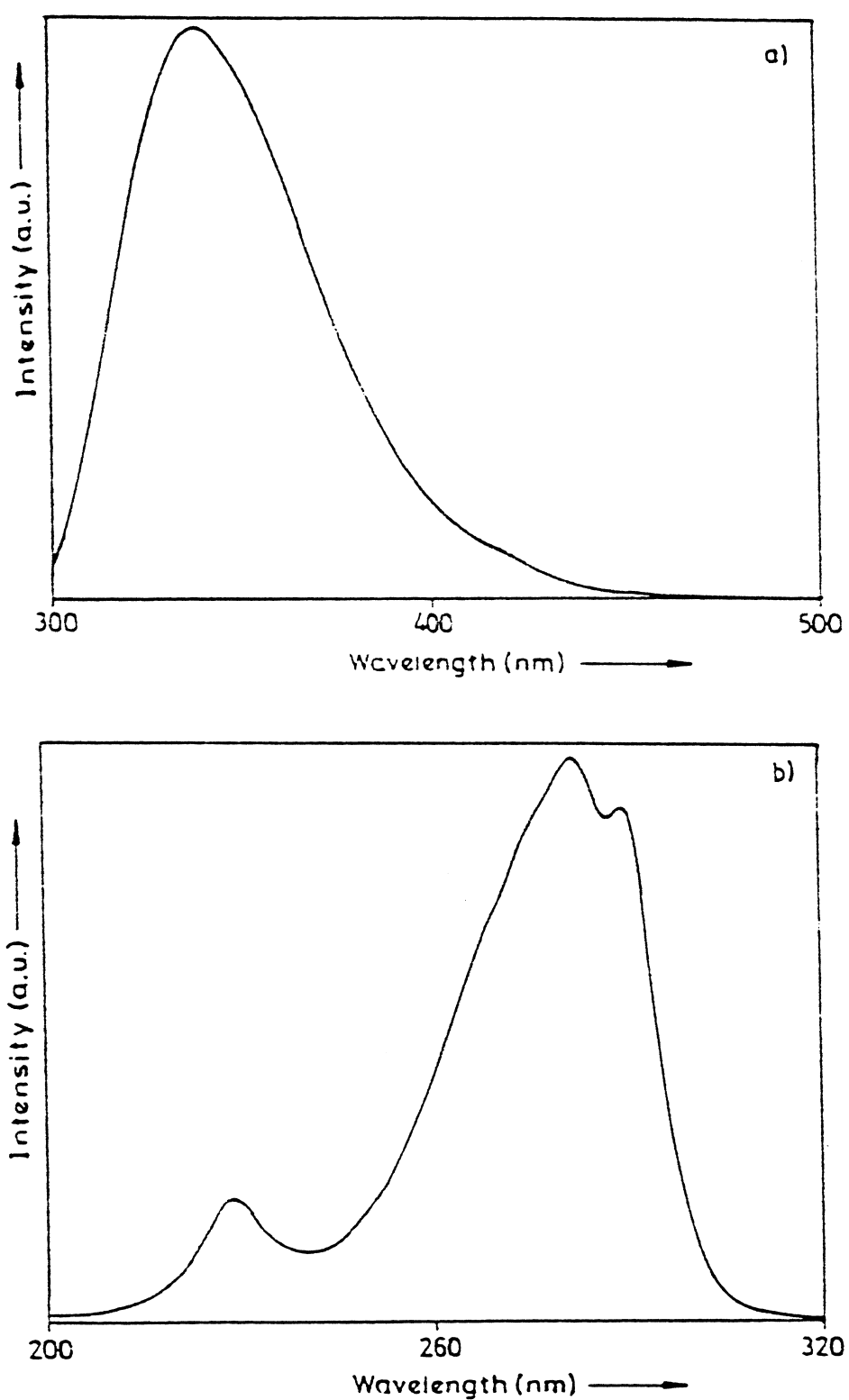

Fig. 1. Fluorescent emission (a) and excitation (b) spectra of [3-(indolyl-3')-2-( $N$-octadecamido)]-methylpropionate (4).

\subsection{Lifetime measurements and polarisation studies}

The fluorescence lifetime and anisotropy data are shown in Table 2. In vesicles, both compounds $\mathbf{4}$ and $\mathbf{5}$ show triple exponential decay as compared to homogeneous solvents where the decay is single exponential (Figs. 3 and 4). Tryptophan itself shows a double exponential decay curve which is explained by the existence of three rotamers $[14,15]$. The triple exponential decay of $\mathbf{4}$ and $\mathbf{5}$ can be due to the presence of three different rotamers and the magnitude of the lifetime values depended on the distance of the acceptor groups from the indole ring (Fig. 5). It has been shown that the most electrophilic group nearer to the indole ring would show a shorter lifetime [14,15]. Accordingly, $\tau_{1}$ corresponds to the rotamer $\mathrm{A}$ in which less electrophilic peptide bond (-NH-CO-) is closer to the indole nitrogen; $\tau_{2}$ corresponds to the rotamer $\mathrm{C}$ in which both the ester and peptide bonds are closer to the indole ring; and $\tau_{3}$ corresponds to rotamer $\mathrm{B}$ in which more electrophilic ester group (as compared to -NH-CO-) is closed to the indole ring. The single exponential decay in homogeneous media may be due to the similar unresolvable lifetimes of rotamers or, due to rapid rotational motion, the lifetimes average to a single exponential. Similar triple exponential decay of a tryptophan-retinal Schiff base has earlier been observed in reverse micellar systems and has been explained by the rotamer model [16]. According to this model during the excited-state lifetime of the molecule there exists conformations around $\mathrm{C}_{\alpha}-\mathrm{C}_{\beta}$ bond that do not interconvert. The different lifetimes of the rotamers arise from different 


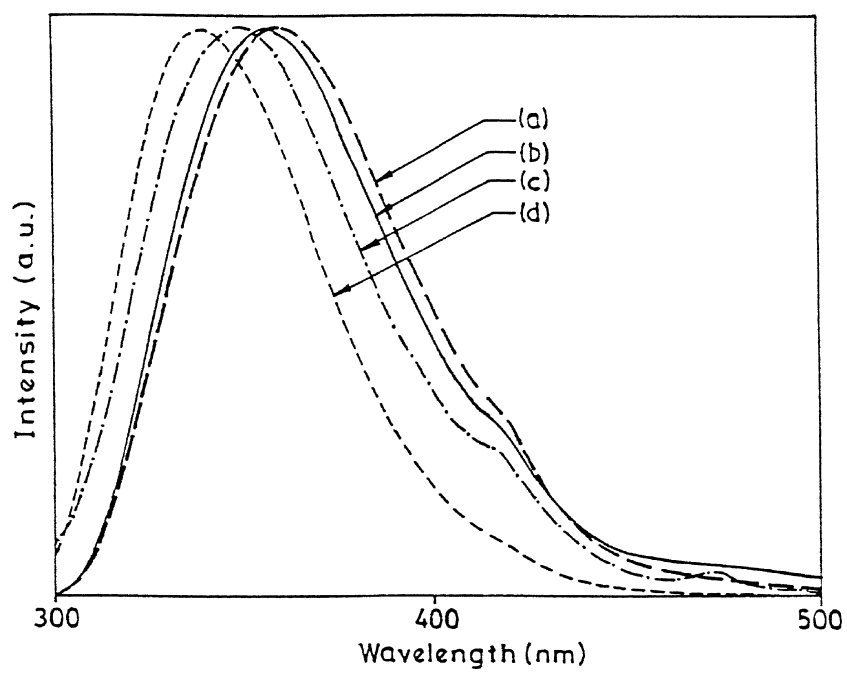

Fig. 2. Fluorescence emission spectra of sodium-[3-(indolyl-3')-2-( $N$ octadecamido)]-propionate (5) in: (a) SDS micelles, (b) methanol, (c) phosphatidylcholine vesicles, (d) THF.

distances of the acceptor group from the indole ring in the charge-transfer interaction. Further, for compound $\mathrm{N}$ acetyl-L-tryptophan ethyl ester also a biexponential decay profile was observed by Petrich et al. [14]. and was explained by the rotamer model taking into consideration the electrophilicities of different acceptor groups.

Organised media responsible for the restricted rotation of the conformers can provide different extent of solvation and hydrogen bonding to the rotamers. The decrease in lifetimes of the fluorophores in phosphatidylcholine vesicles media can also be due to the presence of the carbonyl and phosphate groups in the membrane lipid which can act as quenchers. The reduced lifetime of $\mathbf{4}$ as compared to $\mathbf{5}$ is in agreement [15] with the fact that the quenching efficiency of $-\mathrm{COOMe}$ is greater than that of $-\mathrm{COO}^{-}$.

The motional freedom of a fluorophore is reflected in the values of steady state anisotropy $\left(\mathrm{r}_{\mathrm{ss}}\right)$ which has been
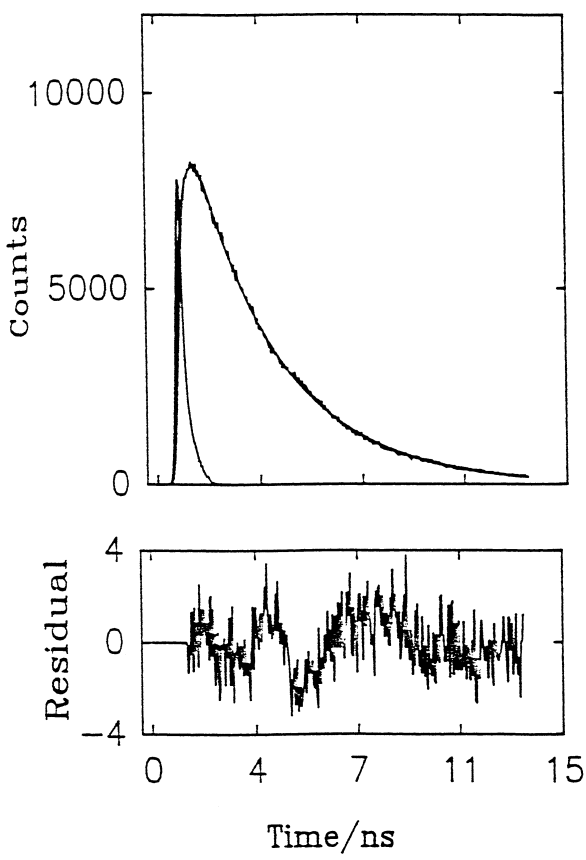

Fig. 3. Fluorescence decay profile for [3-(indolyl-3')-2-( $N$-octadecamido)]-methylpropionate (4) in THF.

examined for compounds $\mathbf{4}$ and $\mathbf{5}$. In homogeneous media the steady state anisotropy values are found to be very low. However, the anisotropy value increases when $\mathbf{4}$ and $\mathbf{5}$ are incorporated in vesicles (Table 2) suggesting that the compounds get to some extent immobilised in the lipid bilayer. The results can be analysed in terms of a form of Perrin relationship [17], $r=r_{0} /\{1+(\tau / \phi)\}$ where $\tau=$ fluorescence lifetime of the fluorophore, $\phi=$ rotational correlation time of the fluorophore, and $r_{\mathrm{o}}=$ anisotropy in highly viscous medium. From the present results it is evident that when the fluorophores are incorporated in vesicles, the lifetime decreases and the anisotropy value increases. This is possible only when $\phi_{\mathrm{r}}$ increases. This means that the solutes are

Table 2

Lifetime $^{\mathrm{a}}$ and anisotropy ${ }^{\mathrm{b}}$ data for [3-(indolyl-3')-2-(N-octadecamido)]-methylpropionate (4) and [3-(indolyl-3')-2-sodium-( $N$-octadecamido)]-propionate (5) in different media at $25^{\circ} \mathrm{C}$

\begin{tabular}{|c|c|c|c|c|c|}
\hline Compound & Medium & Lifetime(ns) & Amplitude & Average lifetime(ns) & Anisotropy(r) \\
\hline \multirow[t]{5}{*}{4} & $\mathrm{CH}_{3} \mathrm{CN}$ & 3.31 & & & 0.002 \\
\hline & THF & 3.14 & & & 0.002 \\
\hline & Vesicle & $\tau_{1}=3.51$ & 0.029 & & \\
\hline & & $\tau_{2}=0.31$ & 0.703 & 0.67 & 0.330 \\
\hline & & $\tau_{3}=1.31$ & 0.268 & & \\
\hline \multirow[t]{5}{*}{5} & $\mathrm{MeOH}$ & 4.03 & & & 0.001 \\
\hline & THF & 4.22 & & & 0.002 \\
\hline & Vesicle & $\tau_{1}=3.33$ & 0.067 & & \\
\hline & & $\tau_{2}=0.38$ & 0.559 & 2.38 & 0.156 \\
\hline & & $\tau_{3}=1.33$ & 0.374 & & \\
\hline
\end{tabular}

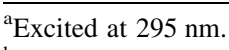

${ }^{\text {b } V a l u e ~ a t ~} 280 \mathrm{~nm}$ with emission at $350 \mathrm{~nm}$. 

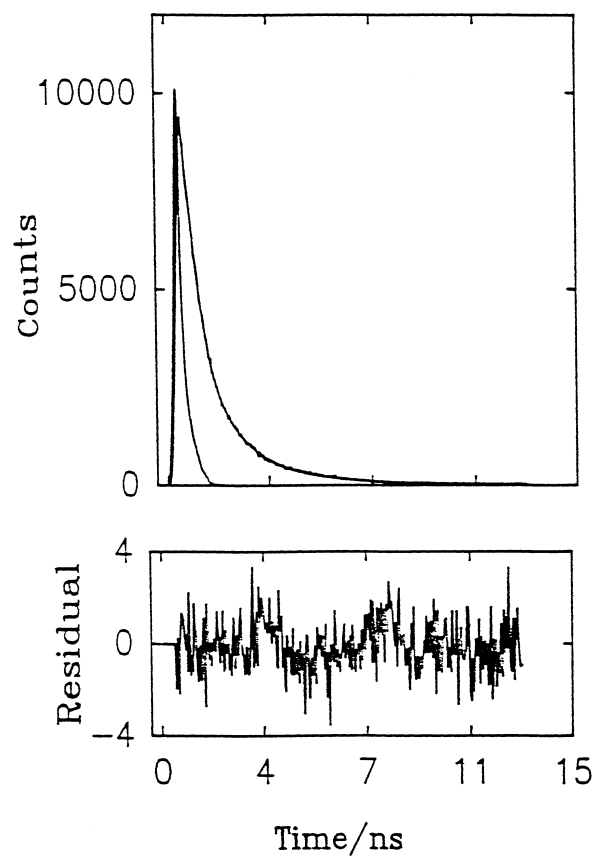

Fig. 4. Fluorescence decay profile for [3-(indolyl-3')-2-(N-octadecamido)-methylpropionate (4) in phosphatidylcholine vesicles.

indeed immobilized in a large particle whose tumbling motion is considerably slower than the fluorescence lifetime.

In comparison to some recently reported interesting probes, viz. 7-aza-tryptophan and $N_{1}$-methyl-7-azatryptophan, compound $\mathbf{5}$ has higher quantum yield and increased lifetime values as compared to tryptophan and 7-azatryptophan but less when compared to $N_{1}$-methyl-7-azatryptophan $^{4}$ (Table 3). Thus, attachment of a long alkyl chain to tryptophan increases $\tau_{f}$ and $\phi_{f}$ which are useful probe properties.

3.3. Quenching of the fluorescence of [3-(indolyl-3')-2-(Noctadecamido)]-methylpropionate (4) and sodium-[3(indolyl-3')-2-(N-octadecamido)]-propionate (5) by retinal and retinol acetate in different media

Since retinylidene polyenes are reported to undergo intimate interaction with tryptophan residues in certain photoreceptors of the opsin family [18-22], we have studied the quenching of the tryptophan fluorescence by retinylidene compounds viz. retinal and retinol acetate. Both retinal and retinyl acetate are found to quench the fluorescence of $\mathbf{4}$ and $\mathbf{5}$. The Stern-Volmer constants $\left(K_{\mathrm{SV}}\right)$ and the quenching constant values are presented in Table 4 and Fig. 6 . It is found that the quenching constant value $\left(k_{\mathrm{q}}\right)$ is more for vesicular media than that for homogeneous media and with the increase in quencher concentration, the emission maxima of both $\mathbf{4}$ and $\mathbf{5}$ shifts towards blue for retinal, but towards red for retinol acetate (Fig. 7).

The quenching constants are found to be unusually high as compared to the normal collisional quenching constant values. Similar type of values were obtained when reverse micellar tryptamine was quenched by retinal. The observed higher quenching constant values in vesicles as compared to organic solvents is due to the close proximity of the probe and the quencher in vesicles whereas they are in random motion in homogeneous medium. Because of the lipophilic nature of the retinoids, their location is in less polar region in the membrane where the probe molecules are located. Thus, efficient quenching is observed. The different types of shift for retinal and retinol acetate shows that they interact differently with $\mathbf{4}$ and $\mathbf{5}$, in both homogeneous and vesicular media. The reason for this shift is not very clear however. This may either be due to the interaction of the surrounding medium with the fluorophore or from the excited state relaxation processes or the combined effect of both.

\subsection{Comparison of the fluorescence of model chromophores with bacteriorhodopsin fluorescence}

The interaction of the tryptophan compounds with retinylidene compounds is relevant to the opsin family of proteins such as bacteriorhodopsin where tryptophan and retinal undergo non-covalent interactions [18-23]. As the protein bound tryptophan residues are buried in membrane bilayer, a comparison of the model compounds in vesicles can be made with the native protein. The structural and functional properties of retinal-proteins are a reflection of the sensitivity of the chromophore with the surrounding apoprotein and the retinylidene chromophore which undergoes intimate interactions with the amino acid residues in the active site. The three dimensional structure of<smiles>COC(=O)C1C2CC3CC(C2)CC1(NC(C)=O)C3</smiles>

$\underline{A}$<smiles>CCOC(C)=O</smiles>

$\underline{B}$

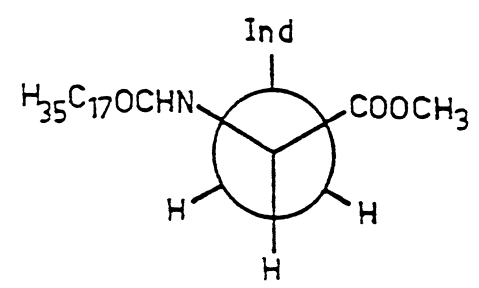

$\underline{c}$

Fig. 5. Possible rotamers of [3-(indolyl-3')-2-[N-octadecamido)-methylpropionate (4) in phosphatidylcholine vesicles. 
Table 3

Comparison of fluorescence quantum yield and lifetime of some tryptophan based compounds

\begin{tabular}{|c|c|c|c|c|c|}
\hline Fluorescence & $4^{\mathrm{a}}$ & $5^{\mathrm{a}}$ & 7-aza-tryptophan ${ }^{\mathrm{b}}$ & $\mathrm{N}_{1}$-methyl-7-azatryptophan ${ }^{\mathrm{b}}$ & tryptophan \\
\hline Quantum yield & 0.15 & 0.21 & 0.03 & 0.53 & $0.135^{\mathrm{c}}$ \\
\hline Lifetime(ns) & 3.14 & 4.22 & 0.78 & 21.70 & $\begin{array}{l}0.620^{\mathrm{d}} \\
3.20\end{array}$ \\
\hline
\end{tabular}

in THF.

${ }^{\mathrm{b}}[6,30]$.

${ }^{c}[11,12]$.

d $[32]$.

Table 4

Results of the quenching experiments for quenching of [3-(indolyl-3')-2-(N-octadecamido)]methylpropionate (4) and sodium-[3-(indolyl-3')-2-( $N$ octadecamido)]-propionate (5) by retinal and retinyl acetate at $25^{\circ} \mathrm{C}$

\begin{tabular}{|c|c|c|c|c|c|c|}
\hline \multirow[t]{3}{*}{ Medium } & \multirow[t]{3}{*}{ Probe } & \multirow[t]{3}{*}{ Average lifetime } & \multicolumn{4}{|l|}{ Quencher } \\
\hline & & & \multicolumn{2}{|l|}{ Retinal } & \multicolumn{2}{|l|}{ Retinyl acetate } \\
\hline & & & $K_{\mathrm{SV}}, 10^{4} \mathrm{M}^{-1}$ & $k_{\mathrm{q}}, 10^{13} \mathrm{M}^{-1} \mathrm{~s}^{-1}$ & $K_{\mathrm{SV}}, 10^{4}, \mathrm{M}^{-1}$ & $k_{\mathrm{q}}, 10^{13} \mathrm{M}^{-1} \mathrm{~s}^{-1}$ \\
\hline$\overline{\mathrm{CH}_{3} \mathrm{CN}}$ & & 3.31 & 3.68 & 1.11 & 4.26 & 1.28 \\
\hline $\mathrm{THF}$ & 4 & 3.14 & 3.56 & 1.13 & 6.58 & 2.09 \\
\hline Vesicle $^{\mathrm{a}}$ & & 0.67 & 6.91 & 10.3 & 2.00 & 2.99 \\
\hline $\mathrm{MeOH}$ & & 4.03 & 3.85 & 0.95 & 2.76 & 0.68 \\
\hline $\mathrm{THF}$ & 5 & 4.22 & 3.45 & 0.81 & 6.84 & 1.62 \\
\hline Vesicle $^{\mathrm{a}}$ & & 2.38 & 19.0 & 7.98 & 4.29 & 1.80 \\
\hline
\end{tabular}

${ }^{\mathrm{a}}$ Phosphatidylcholine, $1 \times 10^{-3} \mathrm{M}$.

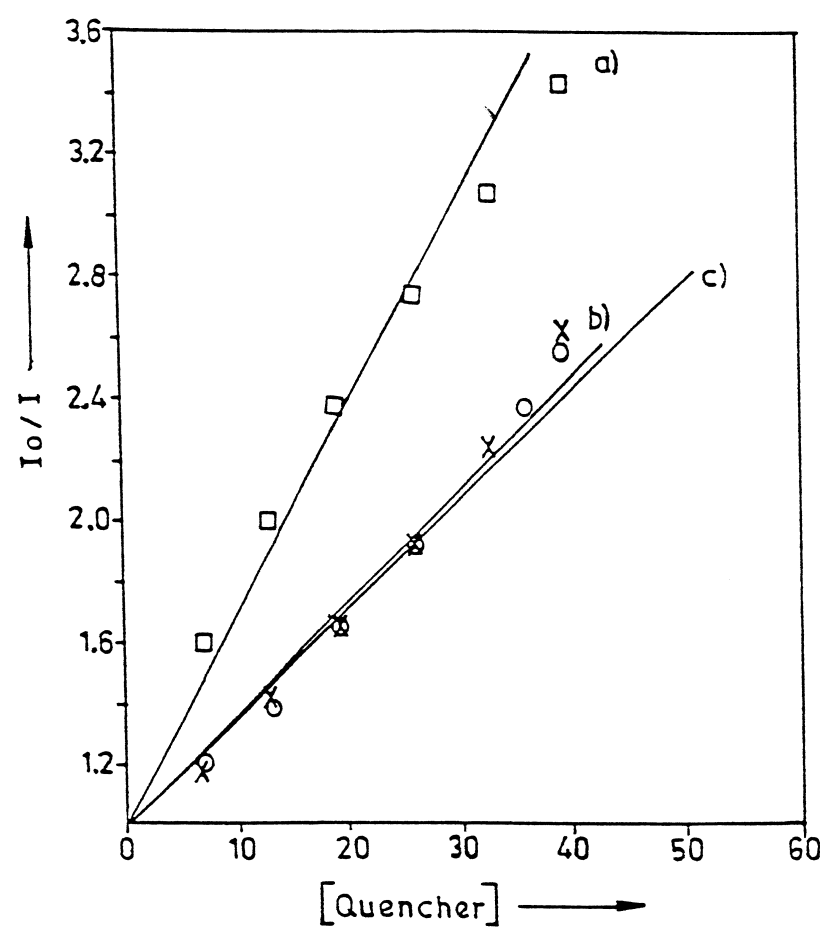

Fig. 6. Stern-Volmer plot for quenching of fluorescence of [3-(indolyl-3' ${ }^{\prime}$ 2-( $N$ - octadecamido)-methylpropionate (4) by retinal in different media: (a) in phosphatidylcholine vesicles, $\square$; (b) in acetonitrile, $\bigcirc$; (c) in tetrahydrofuran, $\mathrm{X}$.

bacteriorhodopsin reveals that several amino acid residues line the retinal pocket in bacteriorhodopsin, with tryptophan (Trp) being the most abundant [four residues: Trp-86 (C-

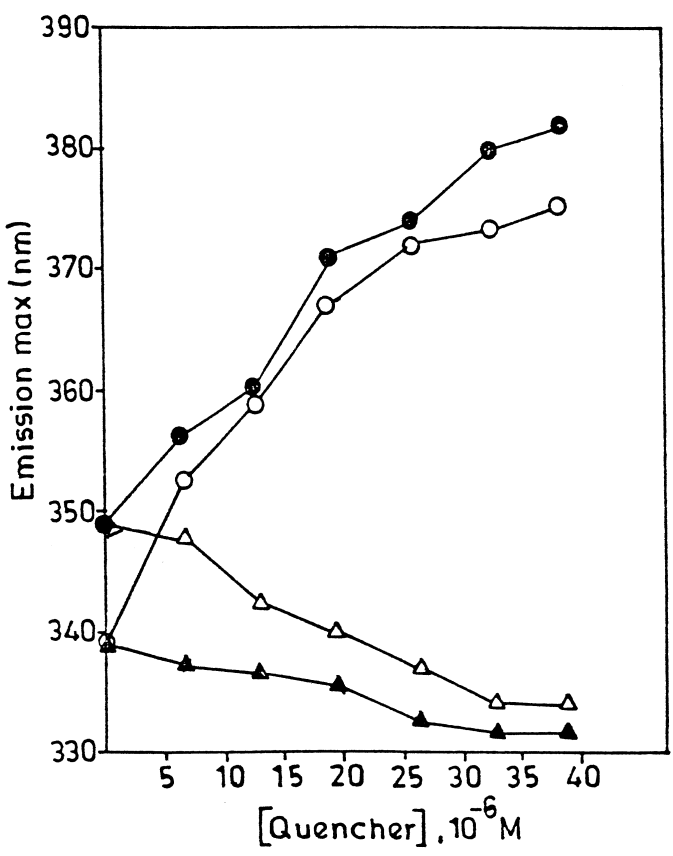

Fig. 7. Shift in the fluorescence maxima of sodium-[3-(indolyl- $\left.3^{\prime}\right)-2-(N-$ octadeca-mido)]-propionate (5) in different media with the addition of quencher: $(\Delta)$ with retinal in THF; $(\boldsymbol{\Delta})$ with retinal in phosphatidylcholine vesicles; $(\bigcirc)$ with retinyl acetate in THF; (O) with retinyl acetate in phosphatidylcholine vesicles.

helix), Trp-138 (e-helix), Trp-182 and Trp-189 (F-helix)] [24]. It is further known that Trp-182 is located above the central polyene chain whereas Trp-189 lies below the $\beta$ - 
ionyl ring forming a sandwich type geometry. While sidechains of Asp, Arg, Tyr, etc. can be directly implicated in the active site electrostatic interaction and proton channelling in bacteriorhodopsin, the role of the tryptophan-residues is far from clear. Mutation of some of these residues affects the conversions among the intermediates of the photocycle of bacteriorhodopsin, (e.g., the L to M conversion [25]) and proton pumping [26]. It has been suggested [27] that Trp-86 is involved in the stabilisation of the side chains of Asp-212 by hydrogen bond to the indolyl NH. Some fluorescence studies on bacteriorhodopsin have shown that Trp can transfer its excitation energy to the retinylidene chromophore in the native protein [28-34]. Recently, Fourier transform infra-red difference spectroscopic studies have indicated the perturbation of $\operatorname{Trp}$ in the $\mathrm{L}$ intermediate [27]. UV spectral changes due to the perturbation of Trp residues in the $\mathrm{L}$ intermediate have also been reported [18]. The mutation of Asp-96 or Asp-115, which are close to Trp182 causes a $1-2 \mathrm{~cm}^{-1}$ shift of the $3486 \mathrm{~cm}^{-1}$ band (due to indolyl NH of Trp) in bacteriorhodopsin. The importance of Trp-retinal interactions has also been highlighted by several other studies [18-22,35]. A theoretical study [35] on the colour control mechanism in retinal proteins has been undertaken and results show that electrostatic interactions between Trp and Tyr residues with respect to the retinal chromophore also contribute to the spectral shifts.

A comparison of the data obtained for $\mathbf{4}$ and $\mathbf{5}$ in vesicular media with the available data [36] for bacteriorhodopsin and bacterioopsin reveals some similarities (Table 5). The steady state fluorescence emission maxima for compounds 4 and 5 in vesicles are 348 and $349 \mathrm{~nm}$ respectively. These are blue shifted as compared to $363 \mathrm{~nm}$ for tryptophan in vesicles. The bacterioopsin fluorescence at $333 \mathrm{~nm}$ which is also blue shifted as compared to $363 \mathrm{~nm}$ of tryptophan in vesicles. The fluorescence emission maximum of bacteriorhodopsin (bacterioopsin + retinal) is blue shifted $(320 \mathrm{~nm})$ as compared to bacterioopsin $(333 \mathrm{~nm})$. Similar types of blue shifts are also found when retinal is added to the vesicular $\mathbf{4}$ and $\mathbf{5}$. The relative fluorescence quantum yields of $\mathbf{4}$ and $\mathbf{5}$ in vesicles have been determined and compared with those reported for various bacteriorhodopsin photocycle intermediates $\left(\mathrm{bR}_{570}, \mathrm{~K}, \mathrm{~L}\right.$ and $\left.\mathrm{M}\right)$. The relative quantum yield for vesicular $\mathbf{4}$ and $\mathbf{5}$ are found to be 0.179 and 0.201 respectively. Upon addition of retinal the values changes as quenching is observed. The relative quantum yields of bacteriorhodopsin fluorescence $\left(\phi_{\mathrm{f}}\right)$ changes from one intermediate to another $\left(\phi_{\mathrm{f}, \mathrm{bR}}=\phi_{\mathrm{f}, \mathrm{K}}=0.15, \phi_{\mathrm{f}, \mathrm{L}}=0.14\right.$, $\phi_{\mathrm{f}, \mathrm{M}}=0.12$ ) indicating the changing conformation of the protein leading to the change in the distance between the protein-bound tryptophan residues and the retinylidene chromophore. The fluorescence lifetime values of the vesicular 4 and 5 are $668 \times 10^{-6} \mathrm{~s}$ and $2.379 \times 10^{-9} \mathrm{~s}$ which differ from the reported lifetime values of tryptophan residues in protein. However, the fluorescence lifetime of the Trp residues in the native bacteriorhodopsin vary with the various intermediates of the photocycle $\left(\tau_{\mathrm{k}}=2.9 \times 10^{-6} \mathrm{~s}\right.$, $\left.\tau_{\mathrm{L}}=58 \times 10_{\mathrm{S}}^{-6}, \tau_{\mathrm{M}}=7.2 \times 10_{\mathrm{s}}^{-3}\right)$. The Stern-Volmer constants $\left(K_{\mathrm{sv}}\right)$ and the rates of quenching $\left(k_{\mathrm{q}}\right)$ were also calculated for all the systems. For the quenching of fluorescence emission of vesicular 4 by retinal, $K_{\mathrm{SV}}=6.91 \times 10^{4} \mathrm{M}^{-1}$ and $k_{1}=2.99 \times 10^{13} \mathrm{M}^{-1} \mathrm{~s}^{-1}$ and for vesicular $5, K_{\mathrm{SV}}=19.0 \times 10^{4} \mathrm{M}^{-1}$ and $k_{\mathrm{q}}=1.80 \times 10^{13} \mathrm{M}^{-1} \mathrm{~s}^{-1}$ were obtained. Similar comparative $K_{\mathrm{sv}}$ and $k_{\mathrm{q}}$ values for the quenching of bacterioopsin fluorescence on incorporation of the chromophore were calculated from the available data [36]. Since the complete removal of the protein-retinal chemical bond (by $\mathrm{NH}_{2} \mathrm{OH}$ treatment) results in an eightfold increase in the protein fluorescence intensity (with respect to native bacteriorhodopsin), $K_{\mathrm{sv}}=4.38 \times 10^{6} \mathrm{M}^{-1}$, $k_{\mathrm{q}} K=1.51 \times 10^{12} \mathrm{M}^{-1} \mathrm{~s}^{-1}, \quad k_{\mathrm{qL}}=7.55 \times 10^{10} \mathrm{M}^{-1} \mathrm{~s}^{-1} \quad$ and $k_{\mathrm{qM}}=6.08 \times 10^{8} \mathrm{M}^{-1} \mathrm{~s}^{-1}$ (using [bR] $-1.6 \times 10^{6} \mathrm{M}$ and the corresponding lifetime values for the $\mathrm{K}, \mathrm{L}$ and $\mathrm{M}$ intermediate). Thus a comparison of the data for vesicular $\mathbf{4}$ and 5 with available data for bacteriorhodopsin reveals the possibility of energy transfer to retinal from tryptophan residues located in the vicinity of the retinal pocket in

Table 5

Comparison of the fluorescence characteristics of the model compounds $\mathbf{4}$ and $\mathbf{5}$ with those of bacteriorhodopsin systems

\begin{tabular}{lll}
\hline Parameter & Bacteriorhodopsin system & $\mathbf{4}$ in Vesicle \\
\hline Fluorescence emission & bacterioopsin 333 & 348 \\
maximum $(\mathrm{nm})$ & bacteriorhodopsin 320 & 349 \\
Relative & $\phi_{\mathrm{f}}, \mathrm{bR}=0.15$ & 0.179 \\
quantum yield & $\phi_{\mathrm{f}}, K=0.15$ & 0.201 \\
& $\phi_{\mathrm{f}}, L=0.14$ & \\
& $\phi_{\mathrm{f}}, M=0.12$ & \\
Fluorescence & $\tau_{\mathrm{K}}=2.9 \times 10^{-6}$ & \\
lifetime(s) & $\tau_{\mathrm{L}}=58 \times 10^{-6}$ & \\
& $\tau_{\mathrm{M}}=7.2 \times 10^{-3}$ & \\
Stern-Volmer constant $\left(K_{\mathrm{SV}}, \mathrm{M}^{-1}\right)^{\mathrm{b}}$ & $K_{\mathrm{SV}}=4.38 \times 10^{6}$ & \\
Quenching constant $\left(k_{\mathrm{q}}\right)\left(\mathrm{M}^{-1} \mathrm{~s}^{-1}\right)$ & $k_{\mathrm{q}}, K=1.51 \times 10^{12}$ & \\
& $k_{\mathrm{q}}, L=7.55 \times 10^{10}$ & \\
& $k_{\mathrm{q}}, M=6.08 \times 10^{-9}$ & $2.99 \times 10^{4}$ \\
& & $19.0 \times 10^{4}$ \\
\end{tabular}

${ }^{\mathrm{a}}[36] \mathrm{K}, \mathrm{L}, \mathrm{M}$ refer to the intermediate in the photocycle of bacteriorhodopsin.

${ }^{\mathrm{b}}$ Obtained by measuring the quenching the protein fluorescence by retinal within bacteriorhodopsin in comparison with bacterioopsin. 
the native protein. Thus retinylidene chain and indolyl moieties in retinal binding photoreceptors may undergo non-covalent interactions. The retinylidene unit can act as a quencher of tryptophan energy, the nature and extent of which depends on the mutual configuration of the fluorophore and the quencher.

\section{Acknowledgements}

Research Fellowship to JD from the Council of Scientific and Industrial Research, New Delhi, Government of India is gratefully acknowledged. We are also gratefully thankful to the Department of Science and Technology and the Board of Research in Nuclear Sciences, Department of Atomic Energy, Government of India, who have provided Research Grants for the purchase of some of the equipment used in these studies. Thanks are also due to reviewer of this paper for his valuable suggestions.

\section{References}

[1] J.M. Beechem, L. Brand, Annu. Rev. Biochem. 54 (1985) 43.

[2] D. Creed, Photochem. Photobiol. 39 (1984) 537.

[3] M. Schiffer, C.-H. Chang, F. Stevens, J. Protein Eng. 5 (1992) 213.

[4] R.E. Jacobs, S.H. White, Biochemistry 28 (1989) 3421.

[5] E. Abel, M.F. Fedders, G.W. Gokel, J. Am. Chem. Soc., 117, 1995, 1265 and references cited therein.

[6] R.L. Rich, A.V. Smirnov, A.W. Schwabacher, J.W. Petrich, J. Am. Chem. Soc. 117 (1995) 11850 and references cited therein.

[7] R.R. Birge, Annu. Rev. Phys. Chem. 41 (1990) 683.

[8] D. Oesterheld, C. Brauchle, N. Hampp, Quart. Rev. Biophys. 24 (1991) 425.

[9] R.A. Boissonnas, St. Cuttmann, R.L. Huguenin, P.-A. Jaquenoud, Ed. Sandrin, Hel. Chim. Acta 41 (1958) 1867.

[10] A.K. Singh, J. Das, Indian J. Chem. 35B (1996) 187.
[11] R.J. Robbins, G.R. Fleming, G.S. Beddard, G.W. Robinson, P.J. Thistlewaite, G.J. Wollfe, J. Am. Chem. Soc. 102 (1980) 6271.

[12] A.K. Singh, M. Roy, J. Photochem. Photobiol. A: Chemistry 51 (1990) 327.

[13] J.R. Lakowicz, Principles of Fluorescence Spectroscopy, Plenum Press, New York, 1983, pp. 345-346.

[14] J.W. Petrich, M.C. Chang, D.B. McDonald, G.R. Fleming, J. Am. Chem. Soc. 105 (1983) 3824.

[15] A.G. Szabo, D.M. Rayner, J. Am. Chem. Soc. 102 (1980) 554.

[16] A.K. Singh, R.V. Aruna, J. Photochem. Photobiol. A: Chemistry 8 (1995) 247.

[17] J.R. Lakowicz, Principles of Fluorescence Spectroscopy, Plenum Press, New York, 1983, pp. 134-139.

[18] D. Kuschmitz, B. Hess, FEBS Lett. 138 (1982) 137.

[19] M. Ishigami, Y. Maeda, K. Mishima, Biochim. Biophys. Acta 112 (1966) 372.

[20] R. Mendelsohn, Nature 243 (1964) 22

[21] K. Shirane, Nature 254 (1975) 722.

[22] R. Bensasson, E.J. Land, T.G. Truscott, Nature 258 (1975) 768.

[23] R. Henderson, J.M. Baldwin, T.A. Ceska, F. Zemlin, E. Beckmann, K.H. Downing, J. Mol. Biol. 213 (1990) 899.

[24] S. Wu, Y. Chang, M.A. El-Sayed, T. Marti, T. Mogi, H.G. Khorana, Biophys. J. 61 (1992) 531

[25] T. Mogi, T. Marti, H.G. Khorana, J. Biol. Chem. 264 (1989) 14197.

[26] A. Maeda, J. Sasaki, Y.J. Okhita, M. Simpson, J. Herzfeld, Biochemistry 31 (1992) 12543.

[27] O. Kalisky, J. Feitelson, M. Ottolenghi, Biochemistry 20 (1981) 205.

[28] W.V. Sherman, Photochem. Photobiol. 36 (1984) 463.

[29] B.J. Plotkin, W.V. Sherman, Biochemistry 23 (1984) 5353.

[30] R.C. Chattelier, P.J. Rogers, K.P. Ghiggino, W.H. Sawyer, Biochim. Biophys. Acta 75 (1984) 776.

[31] P.L. Palmer, W.V. Sherman, Photochem. Photobiol. 42 (1985) 541.

[32] H.J. Polland, M.A. Farnz, W. Zinth, W. Kaiser, D. Oesterhelt, Biochim. Biophys. Acta 851 (1986) 407.

[33] A.K. Singh, M. Roy, J. Photochem. Photobiol. B: Biol. 8 (1991) 325.

[34] D.S. Johnston, A.D. Clark, C.M. Kemp, D. Chapman, Biochim. Biophys. Acta 679 (1982) 400

[35] Y. Beppu, T. Kakitani, Photochem. Photobiol. 59 (1994) 660.

[36] J.M. Fukumoto, W.D. Hopewell, B. Karvaly, M.A. El-Sayed, Proc. Natl. Acad. Sci. USA 78 (1981) 252. 